\title{
The integral as accumulation function approach: A proposal of a learning sequence for collaborative reasoning
}

\author{
Sonia Palha ${ }^{1}$ and Jeroen Spandaw ${ }^{2, *}$ \\ ${ }^{1}$ Centre for Applied Research on Education, Amsterdam University of Applied Sciences, Amsterdam, The Netherlands \\ ${ }^{2, *}$ Engineering, Mathematics and Computer Science, Delft University of Technology, Delft, The Netherlands \\ For correspondence: j.g.spandaw@tudelft.nl
}

\begin{abstract}
:
Learning mathematical thinking and reasoning is a main goal in mathematical education. Instructional tasks have an important role in fostering this learning. We introduce a learning sequence to approach the topic of integrals in secondary education to support students mathematical reasoning while participating in collaborative dialogue about the integral-as-accumulation-function. This is based on the notion of accumulation in general and the notion of accumulative distance function in particular. Through a case-study methodology we investigate how this approach elicits $11^{\text {th }}$ grade students' mathematical thinking and reasoning. The results show that the integral-as-accumulationfunction has potential, since the notions of accumulation and accumulative function can provide a strong intuition for mathematical reasoning and engage students in mathematical dialogue. Implications of these results for task design and further research are discussed.
\end{abstract}

Keywords: mathematical reasoning, collaborative reasoning, secondary education, integral, accumulation function

\section{Introduction}

Mathematical thinking and reasoning is a major goal of mathematics education. From research it is known that tasks that include problem solving, modelling and argumentation provide excellent opportunities to enact students' mathematical thinking (Schoenfeld, 1992). Many topics in secondary education are already taught through tasks of this type (e.g. elementary algebra, exponential functions). However, there are still topics that are traditionally taught formally and mechanically, which makes it difficult for students to think and communicate in conceptual terms. This is the case for the integral concept, which is introduced in most of the European countries in the last two years of secondary education and taught in a procedural way.

Most research concerning the integral concept happened in undergraduate university mathematics (e.g. Thompson, 1994) and focuses on students' difficulties about this topic (Thompson \& Silverman, 2008; Nguyen \& Rebello, 2011) or on its application in the sciences (Nguyen \& Rebello, 2011). Few attempts have been made at high school level (Kouropatov \& Dreyfus, 2013) to develop mathematical tasks that can help students to think and communicate about integrals in more conceptual terms. Based on the research of Thompson \& Silverman we have developed and investigated an alternative approach for secondary education: the integration-as-accumulation-function trajectory (IAF). Additionally, we built on the domain-specific theory of realistic mathematics education (Freudenthal 1991), which provided us with design principles for the learning environment and the tasks. 
In this paper, we describe the IAF approach and we discuss its potential to stimulate mathematical reasoning. The research question that guided the study was:

How can an approach to learning the integral concept based on the notion of integral-as-accumulation-function support the conceptualization of 'integral function' and elicit students collaborative reasoning?

Following a case study methodology, we investigated the research question in the case of one group of three $11^{\text {th }}$ grade students while solving the learning activities proposed in the IAF-approach during four lessons in a classroom. The present study provides an empirically based proposal for an alternative learning sequence about integrals for secondary education and insights about students' actual learning with it. These results can be useful to teachers, curriculum developers and researchers interested in teaching and learning mathematics through dialogue, reasoning and small-group work.

\section{Theoretical framework}

Central notions in our research are 'integral as accumulation function', 'mathematical reasoning' and 'collaborative reasoning'. The theoretical framework behind these notions is described below.

\section{Learning the integral concept}

The development of the concept of 'integral' has shown to be problematic for high school students (Thompson \& Silverman, 2008; Kouropatov \& Dreyfus, 2013). Students' lack of understanding seems to be related to a tendency to focus on procedures and algorithms. Thompson \& Silverman claim that this tendency is probably the result of students' experience with procedural approaches. Also in science disciplines evidence of student difficulties with learning the integral concept has been reported. McDermott, Rosenquist \& Van Zee (1987) reports student difficulties in connecting graphs and physics. According to the authors students have difficulty in forming a mental picture of an object in motion. When interpreting a motion graph such as a velocity versus time graph students do not interpret areas as representing displacement. They "find it difficult to envision a quantity that they associate with square units as representing a quantity with linear units' (p. 506).

Nguyen \& Rebello (2011) investigated students' difficulties in an introductory physics course that deployed solving problems involving integration in the context of electricity. Some common difficulties that students encounter included: setting up and computing the desired integral, determining the limits of the integrals, relating variables in an integral, and computing the integrals algebraically. The major challenges students faced were when they had construct the expression for an infinitesimal quantity and accumulating those quantities in an appropriate manner. The authors attributed students' failure to construct the integral for solving a given problem to students' inability to understand the infinitesimal term in the integral or failure to understand the notion of accumulation of an infinitesimal physical quantity. Students also fail in interpreting the meaning of the area under the curve when they do not understand the structure of the Riemann sum.

Alternative approaches to the learning of integrals have been offered by several researchers at higher education. Tall (1996) recommends the use of dynamic contexts to introduce integrals in a meaningful way. Thompson \& Silverman (2008) propose to use the notion of 'accumulation function', since it is strongly connected to concepts and applications familiar to students, such as total distance, curve length, area, volume, and work. Based on these ideas, Kouropatov and Dreyfus (2013) developed curriculum materials to support the development of the notion of 'integral'. They found that the "integral concept emerges for the students as an abstract construct by vertically reorganizing previous constructs including function, derivative, and infinite sum" (p. 650). 


\section{Mathematical reasoning and thinking}

Reasoning about the accumulative integral function $F(x)=\int_{a}^{x} f(u) d u$ for varying $x$ involves aspects of understanding functions. Research into students' conceptual development of the notion of function (Vinner, 1983; Sfard, 1991; Gray \& Tall, 1994; Slavit, 1997) makes a distinction between an operational or action view on the one hand and an object-oriented view on the other hand. The former sees a function as an input-output process to calculate single function values. In the latter, the function has become an object, which can be the object of an operation, such as differentiation. An object-oriented view of a function admits different representations such as verbal description, graphs, formulas, and tables. It is necessary for reasoning about operations on functions. Furthermore, the object view facilitates reasoning about global (as opposed to pointwise) properties of functions, understanding more advanced concepts from analysis (Slavit, 1997), and establishing a proceptual iunderstanding of functional notations (Gray \& Tall, 1994). This involves the flexibility to think about a function as an action, as an object, and as both.

Another view on the concept function is the process view or covariational view, which involves awareness that the output changes depend on a range of input values and involves a representation of this change. Carlson, Jacobs, Coe, Larson and Hsu (2002) define covariational reasoning 'to be the cognitive activities involved in coordinating two varying quantities, while attending to the ways in which they change in relation to each other' (p. 354). Also, research on the learning of analysis (Rasmussen, Marrongelle, \& Borba, 2014) shows the importance of covariational reasoning for understanding functions and dynamic function relations.

A well founded understanding of the concept function involves therefore the flexibility to think about the integral function within these three views: as an action, as a process, and as an object. It also involves choosing an appropriated view in relation to a particular task. With this definition in mind we investigate students' thinking and reasoning in the case of the integral-as-function.

\section{Collaborative reasoning}

A way to involve students in mathematical thinking and reasoning is through solving tasks in smallgroup work (Dekker, Elshout-Mohr \& Wood, 2004; Webb, Franke, Wong, Fernandez, Shin, \& Turrou, 2014). Solving problems together can foster students' explanations and justifications, because students become motivated to warrant their own ideas and to challenge each other's thoughts (Dekker et al., 2004) and request students to present and discuss arguments can promote rich mathematical discourse, students' use of varied reasoning and clear up some (mis)understandings (Mueller \& Yankelewitz, 2014).

The framework of collaborative knowledge construction (or co-construction) provides an instrument for studying collaborative reasoning (Fischer, Bruhn, Grasel \& Mandl, 2002; Dillenbourg et al., 1995). It distinguishes the following essential processes of knowledge construction in collaborative situations: externalization of task-relevant knowledge, request or elicitation of task-relevant information, overcoming conflict and integrating different perspectives. These processes are enacted by students in dialogue. Externalization of task-relevant knowledge makes it possible for students to clarify different views and opinions. It includes the following dialogic processes:

1) elaborating on each other's views, in which a student takes up an utterance of another student and offers additional information or reworks it (Barron, 2000; Fischer et al., 2002; Yackel, 2002);

2) agreement with someone's contributions and providing answers without further elaboration, which can also indirectly support elaboration by encouraging the group members to keep collaborating (Fischer et al., 2002);

3) answering posed questions, which influences the flow of the dialogue (Barron, 2000). 
Request or elicitation of task-relevant makes possible that knowledge of other students is used as a resource (Fischer et al., 2002) or to clarify a previous action or dialogue (Barron, 2000). It involves the dialogic process of

4) questioning about the task, the mathematics or the strategies used. Posing questions can also help to gain increased knowledge about the mathematical content and its complexity, which contributes to the abstraction process (Williams, 2007).

Acknowledging different views can lead to conflict. When students work together towards a common goal, such as solving a task or evaluating an answer, this requires students to overcome this conflict in order to achieve consensus. The different interpretations made by the students when they are arguing in a conflict situation and trying to reach consensus, stimulate processes which can lead to a modification of knowledge structure (Dillenbourg et al., 1995). Overcoming conflict situations or integrating different perspectives involves dialogic processes such as

5) criticism or rejection of their own or someone's contribution. The contrast of own understanding with other student's understanding can lead to conflict;

6) reconstruction refers to students' reformulation of previous utterances. The occurrence of reconstruction in students' dialogue can be seen as an indication that students are trying to modify their knowledge structure (Dekker and Elshout-Mohr, 1998, 2004). Reconstruction does not necessarily involve new knowledge. Indeed, students may be reconstructing previous ideas as result of overcoming fixations or correction of attention caused by aspects of the task, rather than knowledge or as a reaction to criticism (Dekker et al., 2004).

In our research about the integral concept we study students' learning while solving tasks jointly in small groups. We use the framework in Fischer et al. (2002) and the dialogic processes defined above as an analytical lens to examine students' learning.

The integral-as-accumulation-function approach

Our IAF-approach is based on Thompsons' (1994) approach to the notion of integral and builds on the notion of the accumulation function. The accumulation function associated to a function $f$ is the function $F: x \rightarrow \int_{a}^{x} f(u) d u$. In the teaching materials, the integral is defined as integral function $\int_{a}^{x} f(u) d u$ for varying $x$. The integral is defined as a suitable limit of a Riemann sum $\Sigma f\left(x_{k}\right) \Delta x_{k}$ with positive step widths $\Delta x_{k}$. Thompson (1994) suggests that it is pedagogically advantageous to take initially uniform widths $\Delta x_{k}=\Delta x$ converging to 0 uniformly in $x$ for a range of upper limits $x$ of the integral $\int_{a}^{x} f$. We followed this suggestion. In some tasks, the students could choose a step width $\Delta x=h$ and the intervals in the Riemann sum for themselves. Thompson (1994) suggests that the next step is to understand that the rate of change in $x$ of the integral function $F$ equals $f(x)$. This is the first part of the Fundamental Theorem of Calculus. The integral function $F$ is then characterized by $\boldsymbol{F}^{\prime}(x)=f(x)$ for all relevant $x$ and $F(\alpha)=0$.

In the teaching materials, we therefore used contexts and tasks that could elicit an intuitive notion of (signed) area between the graph and the horizontal axis and intuitive notions of accumulating quantities, such as distance when the velocity graph is given. The idea of accumulation and the concept of function were expected to be familiar to students (in specific contexts such as the accumulated distance) and therefore useful for their thinking and communication about integrals. Here we follow the principle of didactical phenomenology (Freudenthal, 1991) to design the tasks, which rely on the use of contexts that can be meaningful to students as starting points leading to the reasoning about mathematical objects.

The accumulation function is obtained by summing small or infinitesimal multiplicative quantities $f(u) \Delta u$. Mathematically, one should first fix $x$ and then take the limit $\Delta x \rightarrow 0$ in the Riemann sum 
to define the Riemann integral $\int_{a}^{x} f(t) d t$ for this fixed $x$. Next, one can study $F(x)=\int_{a}^{*} f(t) d t$ as a function of $x$, followed by an investigation of its average rate of change $\Delta F / \Delta x$ and its limit $\frac{d F}{d x}$ as $\Delta x \rightarrow 0$. However, as suggested by Thompson (1994), the tasks in the teaching materials simplified this complicated succession of abstract mathematical constructions by allowing the students to study Riemann sums $\Sigma f\left(x_{k}\right) \Delta x$ for varying $x$ and fixed positive step width $\Delta x=h$. Thus, postponing the limiting process $h \rightarrow 0$ facilitates students' intuitive discussion about the average rate of change $\Delta F / \Delta x$ of the accumulation function $F$, potentially leading later on to their learning of the First Fundamental Theorem of Calculus.

\section{The learning sequence in the IAF-approach}

The learning sequence that we developed consists of six lessons, from which four lessons (lessons number 1, 2, 4 and 6) were spent with the collaborative tasks. We'll refer to these as parts I, II, III and IV, respectively. The two remaining lessons were done with a regular textbook. The pre-knowledge to engage in the sequence of tasks includes knowledge about derivatives, a process view of function, rate of change, and an intuitive idea of accumulation. The learning sequence can be found in the appendix.

In a previous study about the learning of integrals, Author (2013) defined key features to develop a more object-oriented view of the integral function. The key features involved authentic contexts, connecting multiple representations, qualitative reasoning and collaborative dialogue. We used these features to develop the learning sequence in the following way:

- Authentic contexts. The tasks involve dynamic contexts about accumulation, such as distance traveled varying over time, because these are authentic contexts to students in secondary education. The context and the open questions allow for a variety of strategies and therefore for different views on functions to occur (integral-as-function as pointwise, process or objectoriented).

- Multiple representations. The students have to relate multiple representations of the integral function, such as tables, formulas, graphs and words. In particular, there are tasks involving covariational reasoning in which students can vary the lower and upper limits of integrals and reflect upon the meaning of the variation.

- Judgements, predictions and explanations. Almost all tasks involve some qualitative reasoning such as judgements about graphs, using representations to understand better or to make predictions about real phenomena and giving explanations.

- Joint solution. The tasks are solved in small groups and the group produces a joint solution. The group is motivated by the teacher to try to solve the tasks and difficulties they face within the group.

We will now discuss the four parts of the learning sequence in general terms. In section 4 we describe in more detail the learning conjectures with regard to each task as used in this article. We select per lesson one or two tasks that we considered exemplary of the learning that took place in that lesson. An overview of the tasks are presented in table 1. We chose to provide the complete description of the tasks in section 4 together with the results about students learning because we think this improves the readability and interpretation of the results.

In parts I and II of the learning sequence the accumulation function is used in specific contexts. For instance, in the tasks 'Train travel' and 'Tachograph' (tasks 1 and 3, Fig. 1 and Fig. 2) the accumulative function takes the form of total distance varying with time. Imagining the total distance varying over time and its relation to a variable speed requires covariation ability. The lessons made students discuss not only the accumulated distance function, but also its rate of change, by eliciting discussions about whether this rate of change increases, decreases or remains constant. Understanding the notion of accumulation function and the rate of this function are expected to lead to an effective intuitive 
basis to other representations of the integral functions such as the construction of graphs, tables and formulas or verbal explanations. Students must interpret, construct and reflect upon graphical and numerical representations of the accumulation function in specific contexts.

In part III of the learning sequence the tasks are meant to support a process view of accumulation functions and therefore elicit co-variational reasoning: one must be able to imagine the values of the accumulation function varying over different values. For instance, in task 11 (Fig. 3) the accumulation function takes the form of the total area under the curve as the vertical line $x=a$ moves to the right, i.e. as the parameter $a$ increases. Students should imagine the graphical representation of this variation and relate the function and its integral. Further, these tasks focus on the relation between different representations (table, graph, words and formula).

The concept of integral function is central in part IV of the learning sequence. For instance, in task 13 (Fig. 4) students explore the meaning of integral function as a process and as an object. Also in this part of the learning sequence students are requested to generate and relate different representations.

Table 1. Learning sequence for the integral concept following the IAF approach

\begin{tabular}{|c|c|c|}
\hline Part & Example & Short description \\
\hline $\mathrm{I}$ & $\begin{array}{l}\text { Task } 1 \\
\text { "Train travel" }\end{array}$ & $\begin{array}{l}\text { A train runs on a railroad track (Fig. 1). A velocity-time graph during a } 40- \\
\text { minute drive is given. (a) What time of the train travel would have been } \\
\text { the most exciting moment for you? Why? (b) Describe the course of the } \\
\text { journey in words, by sketching a distance-time graph and/or a distance- } \\
\text { time table. }\end{array}$ \\
\hline II & $\begin{array}{l}\text { Task } 3 \\
\text { "Tachograph" }\end{array}$ & $\begin{array}{l}\text { A driver plans his trip. He assumes an average speed of } 80 \mathrm{~km} / \mathrm{h} \text { and the } \\
\text { graph is given (Fig. 2) for his } 3 \text { hours trip. (a) Was the average speed } \\
\text { during the trip more or less than } 80 \mathrm{~km} / \mathrm{h} \text { ? Explain; (b) Another driver has } \\
\text { to drive } 240 \mathrm{~km} \text {. He also reckons with an average speed of } 80 \mathrm{~km} / \mathrm{h} \text { but } \\
\text { gets stuck in a jam lasting for one and a half hours. For half an hour he was } \\
\text { forced to drive with an average speed of } 40 \mathrm{~km} / \mathrm{h} \text {. Two options are given. } \\
\text { Draw an appropriate graph for each option. Explain your reasoning. }\end{array}$ \\
\hline III & Task 11a & $\begin{array}{l}\text { Given the function } f(x)=\cos (x) \text { and the graphs (Fig. 3), you can see } \\
\text { how the 'area' of the region enclosed by the graph of } f \text {, the } x \text {-axis and the } \\
\text { line } x=a \text { changes if you take different values for } a \text {. This way you get an } \\
\text { integral function that can be described by } F(a)=\int_{0}^{a} f(x) d x \text { in this } \\
\text { case, } F(a)=\int_{0}^{a} \cos (x) d x \text {. (a) Colour the areas enclosed by the graph } \\
\text { and the horizontal axis and complete the table with approximate values for } \\
F(a) \text {. (b) Sketch the graph of } F(a)=\int_{0}^{a} \cos (x) d x \text {, with } a \text { between } 0 \\
\text { and } 4 \pi \text {. (c) Which conjecture do you have about the relation between } f \text { and } \\
F \text { ? Explain. }\end{array}$ \\
\hline
\end{tabular}




\begin{tabular}{|l|l|l|}
\hline IV & Task 13 & $\begin{array}{l}\text { Given the function } f(x)=\frac{3}{2} x(4-x) . \text { The coloured region is enclosed } \\
\text { by the } x \text {-axis, the graph of } f \text { and the line } x=a \text { starting from } a=1 \text {.The area of } \\
\text { the coloured region can be described using the integral function } \\
F(a)=\int_{1}^{a} f(x) d x . \text { You get different values for the integral function } F \\
\text { as you vary the upper limit } a \text {. Using GeoGebra you'll investigate the graph } \\
\text { of the integral function (Fig. 4). Describe in words using a sketch what the } \\
\text { graph of the integral function looks like. Give a few values of } F(a) . \text { Indicate } \\
\text { how the graph of } f \text { shows whether } F \text { increases or decreases. Explain the } \\
\text { meaning of } F(a)=0 .\end{array}$ \\
\hline
\end{tabular}

\section{Method}

Case study

We investigate the way the IAF-approach contributes to elicit students' mathematical thinking and reasoning using a case study methodology. The case study was conducted following the method proposed by Cobb and Whitenack (1996) to analyse collections of video recording and transcripts of longitudinal data. This approach involves "constantly comparing data as they are analysed against conjectures and speculations generated thus far in the data analysis" (McClain et al, 2001). This method can also be found in the hypothetical learning and teaching trajectories described in (cf. Bakker and van Eerde, 2013).

The case study is a group of three students, whom we refer to as Anne, Brian, and James, from $11^{\text {th }}$ grade (age 16/17 years old). They worked on the tasks described in the appendix for four lessons. They were members in the same classroom, but they were not used to work together. The main corpus of the data are the video recordings and the students' written answers.

The duration of the lessons was 45 minutes. In the collaborative lessons the teacher initiated and ended the lesson with the whole class. During the rest of the lesson the 3 students worked solely in their group. The teacher supported them when they asked for help.

\section{Analyses of collaborative mathematical reasoning}

The data analyses were mainly qualitative and partially deductive and inductive. They involved: (i) analysis of the collaborative dialogue and written solutions, (ii) analysis of the reasoning about the integral-as-function, and (iii) analysis of the actual learning with the tasks.

Analysis of students' collaborative knowledge construction was based on the framework of Fischer et al. (2002). The framework informed the initial development of categories that were later on refined. Students' dialogue during the four lessons with the learning sequence were transcribed and analysed at utterance level. Each utterance falls into one of the categories 'agreement', 'answering', 'elaboration', 'questioning', 'criticizing' or 'reconstruction' (see appendix).

To analyse students' understanding of the concept integral function we attended to the way students' reasoning included aspects related with a particular view of function (action view, process view and object-oriented view). We applied the action-object theory from Sfard (1991) and the process view from Carlson et al. (2002) to identify aspects of students' conceptualization of the integral function (see Table 2). We also attended to the way students refer to elements of the specific context of the task and in relation with mathematical terms. For instance, explanations referring to elements of the mathematical representation (e.g. "the graph is steeper") are closer to mathematical discourse than explanations using elements of the phenomena ("the train runs faster"). At last we reflect on students' learning with the specific tasks by comparing the conjectured learning and the actual learning 
observed (Tables 6-10). The result of this reflection help us to develop the IAF-approach further and revise the learning sequence.

Table 2. Analysis of students' mathematical understanding of the integral function

\begin{tabular}{|l|l|l|}
\hline & Concept Integral-as-Function & Example \\
\hline $\begin{array}{l}\text { Operational } \\
\text { view }\end{array}$ & $\begin{array}{l}\text { Students calculate the output value for a } \\
\text { specific function value of the integral. }\end{array}$ & $\begin{array}{l}\text { At 4 second is the distance 100 } \\
\text { meters. }\end{array}$ \\
\hline Process view & $\begin{array}{l}\text { Students imagine the output values of the } \\
\text { integral function changing depending on a } \\
\text { range of values of the input. }\end{array}$ & $\begin{array}{l}\text { The distance increases as the value } \\
\text { of } t \text { increases. }\end{array}$ \\
\hline $\begin{array}{l}\text { Object-oriented } \\
\text { view }\end{array}$ & $\begin{array}{l}\text { Students recognize or use different } \\
\text { descriptions of the same mathematic object } \\
\text { (integral function) and refer to its } \\
\text { characteristics. }\end{array}$ & $\begin{array}{l}\text { The students relate a numerical and } \\
\text { graphical representation of the } \\
\text { same integral. }\end{array}$ \\
\hline
\end{tabular}

\section{Results}

In the six subsections below we present the results of the actual students' learning of the integral concept and to what extend the tasks involved the students (individually and as group) in mathematical reasoning and collaborative knowledge construction. These results are detailed per task and in chronological order.

Intuitive understanding of the integral concept

Initial conjectures about students' learning. The focus of the first lesson was to elicit an intuitive understanding of the integral function given a specific context. Task 1 train travel (Fig. 1) was meant to introduce two main ideas that underlie the notion of integrals: rate of change (task 1a) and accumulation function (task $1 b$ ).

The task uses the context of velocity and distance, which is familiar to students. The questions are open. We conjecture that it elicits different strategies and explanations.

A train runs on a railroad track. The speed is measured every minute. The graph below shows the results of the measurements during a 40-minute drive. From the velocity-time graph it is possible to deduce how far the journey was.1a: Imagine that you were in the train.

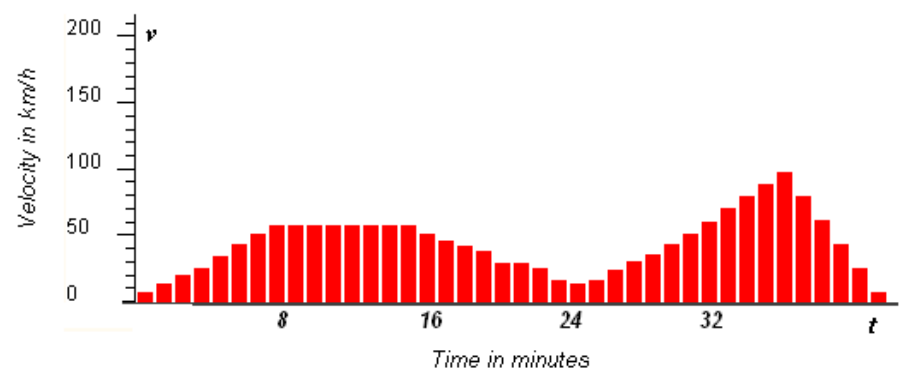

a. What time of the train travel would have been the most exciting moment for you? Why?

b. Describe the course of the journey in words, in terms of distance covered as a function of time. Back up your description by sketching a distance-time graph and/or a distance-time table. Explain.

Figure 1. Task 1 Train travel 
In task 1a the velocity varies over time and therefore the rate of change varies. We conjectured that students imagine the accumulated distance varying over time and its relation to a variable speed. They imagine the rate of change of the accumulated distance increasing, decreasing or remaining constant.

Collaborative mathematical reasoning with task 1a. Analysis of the group dialogue showed that students' descriptions and explanations were initially phenomenological. Students discuss which is the most trilling moment [16]-[25]. Anne thinks that must be the moment at which the train goes fastest [17]. Brian thinks it should be the moment of breaking [20]. James disagrees: he states that it must be the moment of accelerating [24].

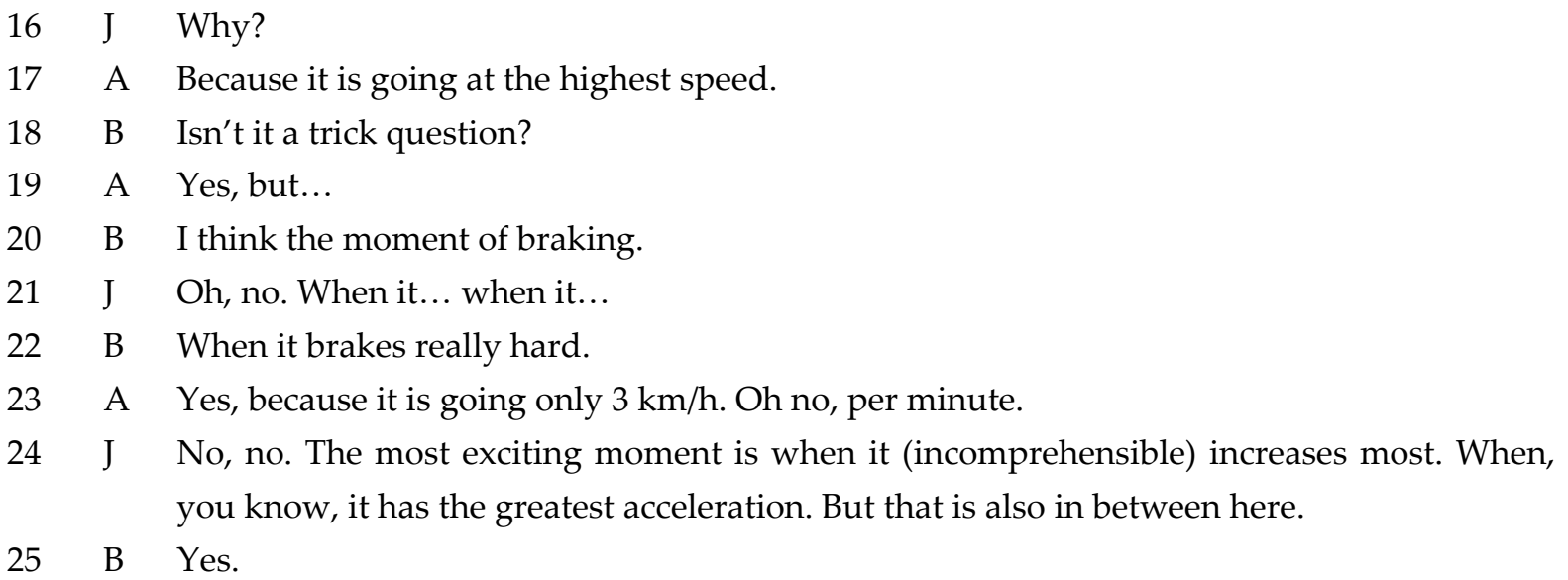

Through the dialogue students modified their descriptions and explanations several times, mostly as response to other students' elaboration or critique. As we see in [26]-[49] each of the students modified his or her previous description of the rate of change. Anne, who initially used the words 'highest speed' [17], used later the term 'steeper' [26] (reconstruction) to explain the graph. She explicitly elaborates the relation between the contextual and the graphical description in [30]. Finally, she uses the term 'change' [48]. She does this as reaction to James critique about the formulation of the answer [46] and Brian attempts to elaborate his description [47].

In the case of James, the initial statement 'increases most' and 'the greatest acceleration' [24] are reconstructed in 'steeper' [33] and later on reconstructed as 'change' [46]. He does this while rejecting Brian's description and accepting Anne's statement. In fact, James selects Anne's proposal and extends it: 'The change of the speed is greatest, not highest.'

Brian also elaborates his initial description 'the moment of breaking' [20] or 'hard breaking' [22]. He reconstructs this to 'steeper' [27] and relates this to 'quick breaking'. Brian keeps on elaborating previously made descriptions in contextual terms such as in [45] and [47]. Although Brian accepts the description formulated by James and Anne, there is no evidence that he modifies his own description further than 'steeper'.

26 A Or when it suddenly brakes, here. That is even steeper.

27 B Yes, that is really steep. That's is what I meant, when it brakes really quickly. So here.

28 J Yes, what is more exciting? Acceleration or braking?

29 B ...when it decelerates really, really quickly, like, whoo...

30 A This is steeper than this, so this goes (changes?) faster

$31 \mathrm{~J}$ Yes, but acceleration is also exciting. 


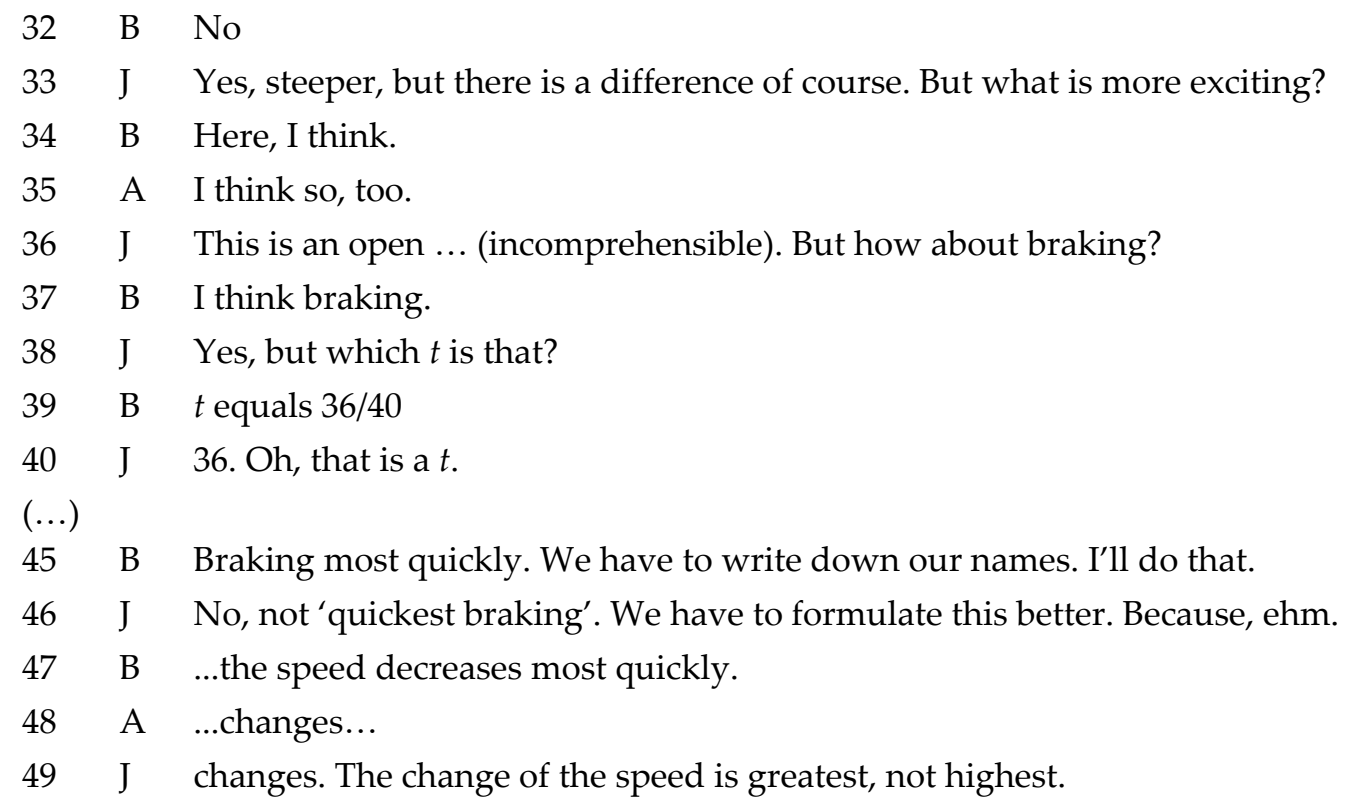

Students worked together in task $1 \mathrm{a}$ and showed effort in producing a joint explanation and solution to the task. They finally agreed on a more general explanation (Fig 2).

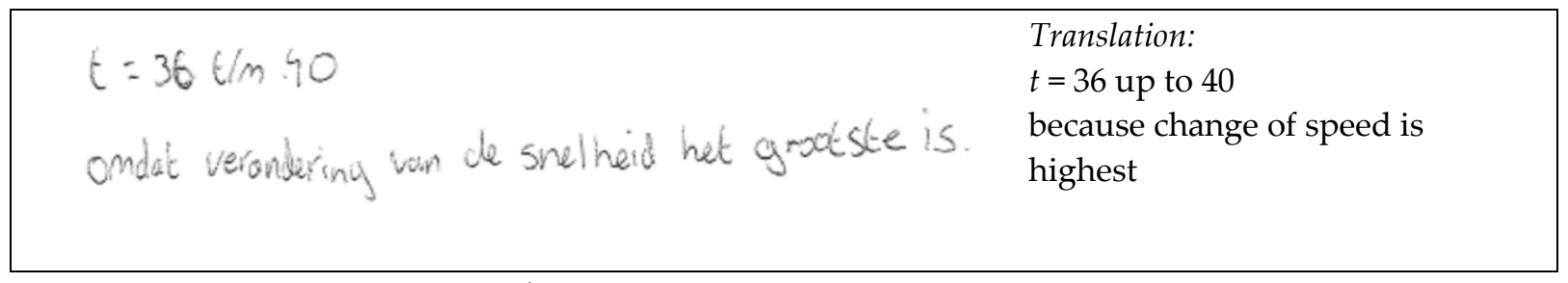

Figure 2. Students' solution to task 1a

The modification in the dialogue occurred sometimes as an elaboration of their previous explanation, sometimes as a reaction to each other's utterances. One way or other, the collaboration elicited the modification. In particular, there were two contributions of students to the group dialogue that took the modification to a more general level: the introduction of the term 'steeper' [26] by Anne, which was further adopted by Brian and James. The formulation of the found solution in mathematical terms by James [49] was a result of multiple elaboration on each others utterances [45]-[49].

Reflection on actual and conjectured learning. Aspects of the task have contributed to the processes described above. The contrast between accelerating and breaking, which was induced by the context of the task have motivated students to discuss the steepness of the graph and to communicate about it. The rate of change can be interpreted in terms of phenomena as the "train goes faster" or "the velocity is higher" in a certain interval of time. It can also be interpreted in graphical terms ("the graph is steeper") and in more general terms as "the slope changes". Thinking in general terms can be considered more sophisticated than thinking in terms of the phenomena, since it goes beyond the specific context and pragmatic reasoning. The need to produce a joint and written explanation may have motivated students to re-formulate their own explanations in a more sophisticated manner.

We had expected that task 1a (and 1b) would elicit intuitive notions of accumulating quantities, but we did not observe in students dialogue or written answers evidence of this. Also we did not observe students' reasoning about the accumulated distance varying over time or about the rate of change of the accumulated distance increasing, decreasing or remaining constant. Table 3 summarize essential aspects of the actual learning and aspects of the task that may have supported this learning. 
Table 3. Actual learning with task $1 \mathrm{a}$ and aspects of the task

Actual learning and collaborative reasoning

Phenomenological and context specific

- Students discuss the different steepness of the graph within the phenomena, graphic and general.

\section{General description of the rate of change}

- Students share, relate and modify different descriptions of the rate of change; they go beyond the specific task setting and use general terms such as steepness of the graph and change.

- Students jointly produced a general description of the rate of change.

\section{Aspects of the task that supports the learning}

- $\quad$ The context velocity-graph with varying velocity.

- $\quad$ The contrast between accelerating and breaking, induced discussion about the graph steepness

- $\quad$ Students worked towards to produce a joint explanation and written solution.

Numerical representation of the integral-as-accumulation function

Initial conjectures about students' learning. In the task train travel (Fig. 1) the accumulated distance varies over time and students are required to produce a mathematical representation of this variation at their choice. Since the velocity is not constant, this variation cannot be simply represented in a single formula or a simple graph. Students must imagine and describe for themselves how the accumulated-distance varies over time.

1. We expected that students imagine the rate of change of the accumulated distance as increasing, decreasing or remaining constant.

2. We conjectured that the context of total distance supported by the bar-graph Fig. 1 elicit the thought that the accumulation function is obtained by summing small or infinitesimal multiplicative quantities $f(t) \Delta t$.

3. The description can be in words in which the growth of the accumulated distance values is given and in relation with the time. It can also be a table with accumulated values or a graph that represents an increasing curve. Hypothetically, the construction of a mathematical representation requests that students imagine the integral function in different manners as an action, as a process of as an object. Because students may think differently we conjecture that in the dialogue several views will be discussed, shared and modified, and that initial explanations will become more mathematically sophisticated.

Collaborative mathematical reasoning. Analysis of students' reasoning showed that the construction of a mathematical representation of the total distance function was a challenge for the three students. Since the very beginning of the solution process, the students were having trouble unravelling the meaning of 'distance as a function' and imagining the accumulated distance as a function varying over time. The intuitive notion that the total distance is a quantity that accumulates may however help students to overcome this difficulty, because it helps them to initially imagine the correspondence between time and total distance and try to construct this correspondence pointwise. This is what we observe in fragment 2, utterances [17]-[29]. James seems to conceptualize the total distance as a function of time [17] and Anne seems to share similar though as she suggests to construct a table [18], which is a way to represent a pointwise relation. But next, we observe students struggling with the construction of the table. Initially, they don't know which moments they should consider [19]. At a certain point James notices that they should calculate the distance for each of the small intervals and that the total distance with be the sum of them all [75]. Anne elaborates on James's idea and suggests to take the average distance [77]. 
17 J OK, OK, OK. So you can substitute time. And the distance covered... here it is in kilometre per minute. So you can, eh, so you have to compute the total distance.

18 A Yes, maybe we have to make a table first.

19 J Yes, one can make that table, but which points in time do we take? 8, 16, 24, or any time something is going to happen?

(...)

74 B So let's start with that. Shall we just take all these points, the points below?

$75 \mathrm{~J}$ Yes, but if you take 8, then you have to compute this one and this one and this one and this one and this one and this one and this one and add all those. Only then you'll have the distance.

76 B OK, I can't read it properly.

77 A No, that is true. Don't we have to take the average distance and then compute the speed or something like that?

$78 \mathrm{~J}$ Yes, that is much smarter.

The students calculate together the average velocity and multiply this with the time interval. Sometimes they took the whole interval (from 8 to 15) [130], whereas other times they were calculating per bar (they calculate the distance for each interval with length 1). In the answer (Fig. 3) they only register the values over the whole interval. The students established the intervals based on the speed: increasing, constant and decreasing.

Initially only James was thinking in terms of accumulated distance [133], [139] and [140]. In order to produce the answer 11 James must have thought something like "for $t=8$ we get $s=4$ and for $t=15$ we get $s=4+7=11$ ". This way of thinking involves an understanding of distance as an accumulation function. Anne and Brian were not thinking in this terms as we deduct from [136] an [137]. They were probably thinking about the distance-function (and not the total distance). Anne's rejection of James' solution [136] induced James to elaborate an explanation twice [138] and [140]. It helped Anne and Brian to think in terms of the accumulated distance [141] and [142].

$\begin{array}{lll}130 & \text { B } & \text { From } 8 \text { to } 15 \\ 131 & \text { J } & \text { Yes, } 7 \\ 132 & \text { B } & 7 \\ 133 & \text { J } & \text { Yes, but then it has to be } 11 . \\ 134 & \text { B } & 123, \text { yes } 7 \\ 135 & \text { J } & \text { is 11 } \\ 136 & \text { A } & \text { Uh? I don't understand a thing. } \\ 137 & \text { B } & \text { No. } \\ 138 & \text { J } & \text { You have to add them, the distances. } \\ 139 & \text { B } & \text { Yes, you have to add them, yes. } \\ 140 & \text { J } & \text { So the travelled distance is } 11,4+7 \text { is } 11 \\ 141 & \text { B } & 11 \\ 142 & \text { A } & \text { Oh yes, I get it. }\end{array}$




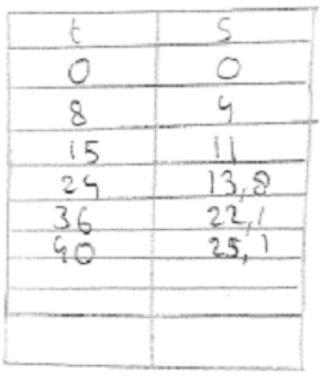

Figure 3. Students' solution to task $1 \mathrm{~b}$

From this moment the students could solve the task without major problems. However there are two situations that are worth to mention: the first one is that students realize that the average speed can be negative but the accumulation function is still an increasing function [155].

$155 \mathrm{~J}$ It is possible, deceleration. It is about travelled distance, so if you start covering less distance, then you still cover some distance.

The second situation is that Anne discover that the accumulated distance can be seen as the area under the graph [158], knowledge that she probably learned in science class. The others also recognized this after Anne have noticed it [159] and [161].

158 A Ah, but I know it. $s$ is just the area under the graph, isn't it?

159 B Ah, yes...

160 A Yes, yes

161 J But that is just 0.5 times, yes, that is the same.

Reflection on actual and conjectured learning. Comparing the initial conjectures about students' learning with the actual observed learning of the three students we realize that the construction of the mathematical representation was a bigger step for the students than what we expected. This seems to be connected with students' difficulty to conceptualize the accumulation-function. The students have finally produced a numerical representation but this took much time; the collaborative setting was essential to overcome their difficulty. This process is summarized in Table 4.

Table 4. Actual learning with task $1 \mathrm{~b}$ and aspects of the task

Actual learning and collaborative reasoning

Numerical representation (table) of the accumulated distance involving action view

- Students generate verbal explanations and numerical representations about accumulated function in the specific context of total distance.

- They struggle with the construction of the numerical representation because they don't know initially which moments (values of $t$ ) they should consider to construct the pointwise function (which is needed to construct the table).

- Understanding that deceleration means that there still is some distance travelled helped to construct an increasing graph.

Different meanings of accumulated distance, including area under the graph

- Students share different perspectives and strategies for calculating the total distance: using the formula for the average velocity, using the area under the graph and imagining the accumulated function varying over time.

Accumulated distance as the sum of multiplicative quantities 
- To generate the table the students calculate the values for the accumulated distances by multiplying the average velocity with the time interval. Sometimes they take the whole interval (from 7 to 15), whereas other times they were calculating per bar (time step).

\section{Aspects of the task that supports the learning}

- The context of the train travel and the bars in Fig. 1 help student to generate an image of the total distance per time interval and to understand that deceleration means that there still is some distance travelled. Furthermore, it elicits the idea that the accumulation function is obtained by summing small or infinitesimal multiplicative quantities $f(t) \Delta t$.

- The situations of deceleration provoked the discussion about properties of the accumulation function.

- The open questioning together with the collaborative setting elicits a variety of mathematical representations/different views.

- It requires a joint solution.

\section{Graphical representation of the accumulated distance}

Initial conjectures about students' learning. In tachograph task (Task 3, Fig. 4) the accumulation function takes also the form of accumulated distance: the velocity of a bus varies with the time and students must interpret, analyse and generate graphical representations of the total distance.

1- We expected that in task $3 \mathrm{~b}$ students generate a graphical representation of the total distance and that interpreting the graph in Fig. 4 would help students to imagine the representation.

2- We conjectured that task $3 \mathrm{~b}$ elicits students' talk about the average rate of change of the accumulating distances; that this would elicit covariational reasoning and therefore stimulate students to conceptualize the total-distance-function as a process.

A tachograph is a device that measures the speed of a vehicle. In the figure below you see an unfolded tachograph used in road transport and a digital tachograph. Tachographs are used mainly to monitor trucks and to check whether the driver abides by the rules for rest times. A tachograph is connected to the propulsion (usually to the gear box). This way the speed $v$ (in $\mathrm{km} / \mathrm{h}$ ) is registered.

A certain driver plans his trip. He assumes an average speed of $80 \mathrm{~km} / \mathrm{h}$. In the graph below you'll find the graph depicting his 3 hours trip. In the graph, $t$ is time measured in hours.

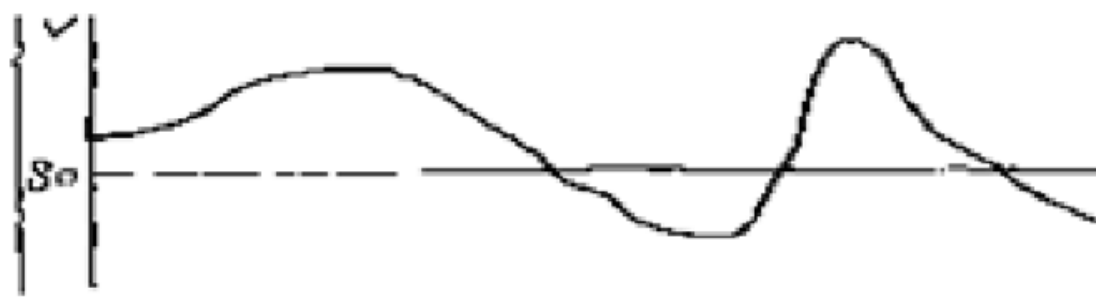

a. Was the average speed during the trip more or less than $80 \mathrm{~km} / \mathrm{h}$ ? Explain.

Another driver has to drive $240 \mathrm{~km}$. He also reckons with an average speed of $80 \mathrm{~km} / \mathrm{h}$. Unfortunately, this driver gets stuck in a jam lasting for one and a half hours. For half an hour he was forced to drive with an average speed of $40 \mathrm{~km} / \mathrm{h}$. He now has two options:

Option 1: Drive with an average speed of $80 \mathrm{~km} / \mathrm{h}$ and accept that he won't make the $240 \mathrm{~km}$.

Option 2: Drive faster during the last hour and still make the $240 \mathrm{~km}$.

b. Draw an appropriate graph for each option. Explain your reasoning.

Figure 4. Task 3 Tachograph

Collaborative mathematical reasoning. In solving task 3a the students state that most of the line is above the 80 . The graph is interpreted by each of the students differently; they communicate their thoughts 
but they don't seem to listen carefully to each other. They seem to assume that they are talking about the same thing. There is little evidence of co-construction.

Analysis of the group dialogue in task $3 b$ showed that students discuss initially how they should approach the task. They had doubts about which representation they should construct (velocity-time or distance-time). The idea of constructing a graph, proposed by Jesse is elaborated by the three students. But also criticized and questioned by the students. They finally conclude that the two situations are correct as for each of them it is possible to construct a representation. Finally, they opted for a distance graph (see fig 5). The students first constructed a distance-time and then they extended it to meet options 1 and 2.

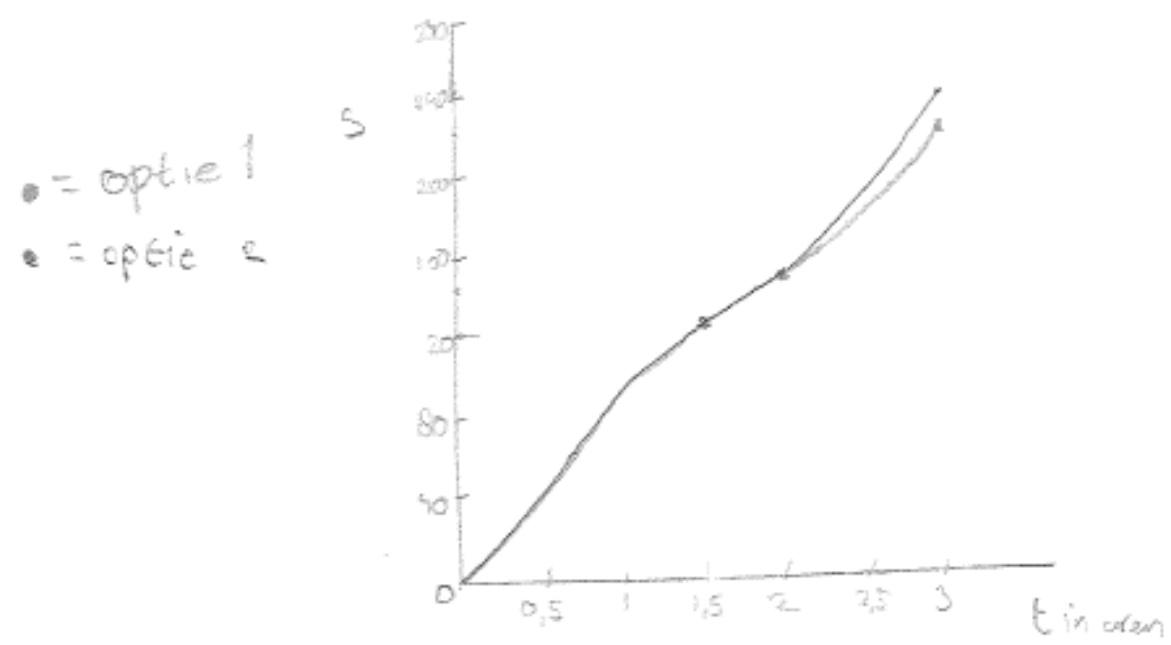

Figure 5. Students' solution to task 3

While students were constructing the distance graph they were trying to imagine what the graph would look like [106]-[108]. Brian mentions the relation by stating that it 'increases steadily', which suggests that student is thinking in covariational terms. Students' wording contains much terms of the context specific of the task such as 'going up'.

106 B So first it goes steadily, it becomes 120 . The first 1.5

107 J Yes, so what?

108 B The first 1.5 hours it increases steadily to 120 . So it is just a straight line.

Reflection on actual and conjectured learning. Although in a limited manner the students did engaged in covariational reasoning with task 3 . That occurred when solving part $b$ of the task. The reasoning and students wording remain however context-specific. The first part of the task induced reasoning that involved thinking about the integral as an area. Looking back to the initial conjectures about students learning we see few reasoning involving the average rate of change. Table 5 summarizes aspects of the actual learning of students with task 3 and aspects of the task that support it.

Table 5. Actual learning with task 3 and aspects of the task

\section{Actual learning and collaborative reasoning}

Thinking and interpretation of velocity graph

- Students interpret the velocity graph qualitatively (most of the line is above the 80 )

Doubt about the best graph to use

- Students doubt and discuss about which graph would be the best one to solve the task 
(velocity-time or distance-time). They opt for distance-time because this is more efficient. Graphical representation of an accumulated distance graph involving a process view

- Students draw a global distance graph and while they are constructing they share their thoughts about what the graph would look like.

- Students' wording (e.g. 'increases steadily') suggests that students share a process view of accumulated distance-function (context specific).

Aspects of the task that supports the learning

- Providing the velocity graph and asking about the average speed .

- Choosing for the graph themselves provoke doubts and discussion .

- Comparison of two options motivated students to think about the graphs.

- Asking for a global representation (instead of drawing in detail) elicits students to reason using covariation.

- It requires a joint solution.

\section{Rate of change of the accumulation function}

Initial conjectures about students' learning. In task 11 (Figure 6) the integral function takes the form of the accumulated area function. Students are requested to colour the area under the graph of a periodical function as the upper limit varies and give the value of the integral function by each coloured area. In the first part of the task the graph of the sine function is given and the student should colour the area under the curve between $x=0$ and $x=a$ as $a$ increases.

1. We conjectured that this task supports students to imagine the values of the accumulation function varying over different values because students are explicitly required to provide numerical values associated with each area. Students are then requested to present a graphical representation.

2. We expected that students would imagine and relate different representations (graph, words and formula) of the integral function.

3. One misconception about integrals when this subject is approached as the area under the curve is that the integral values should be always positive because they represent areas. With task 11 we expect that some students would initially reason in this way but then they would realize that this is not true.

4. Because students already have learned that the cosine is the derivative of the sine function, we conjectured that students would recognize this relation (part c) and realize that the integral can also be ale antiderivative.

Let $f$ be the function $f(x)=\cos (x)$. In the series of graphs below, you can see how the 'area' of the region enclosed by the graph of $f$, the $x$-axis and the line $x=a$ changes if you take different values for a. This way you get an integral function that can be described by $F(a)=\int_{0}^{a} f(x) d x$ in this case, $F(a)=\int_{0}^{a} \cos (x) d x$. You also see the approximate values of the integral function for certain values of $a$.

Colour the areas enclosed by the graph and the horizontal axis: green for areas above the axis, red for areas below the axis.

Complete the table with approximate values for $F(a)$.

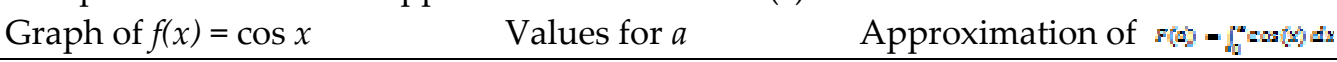




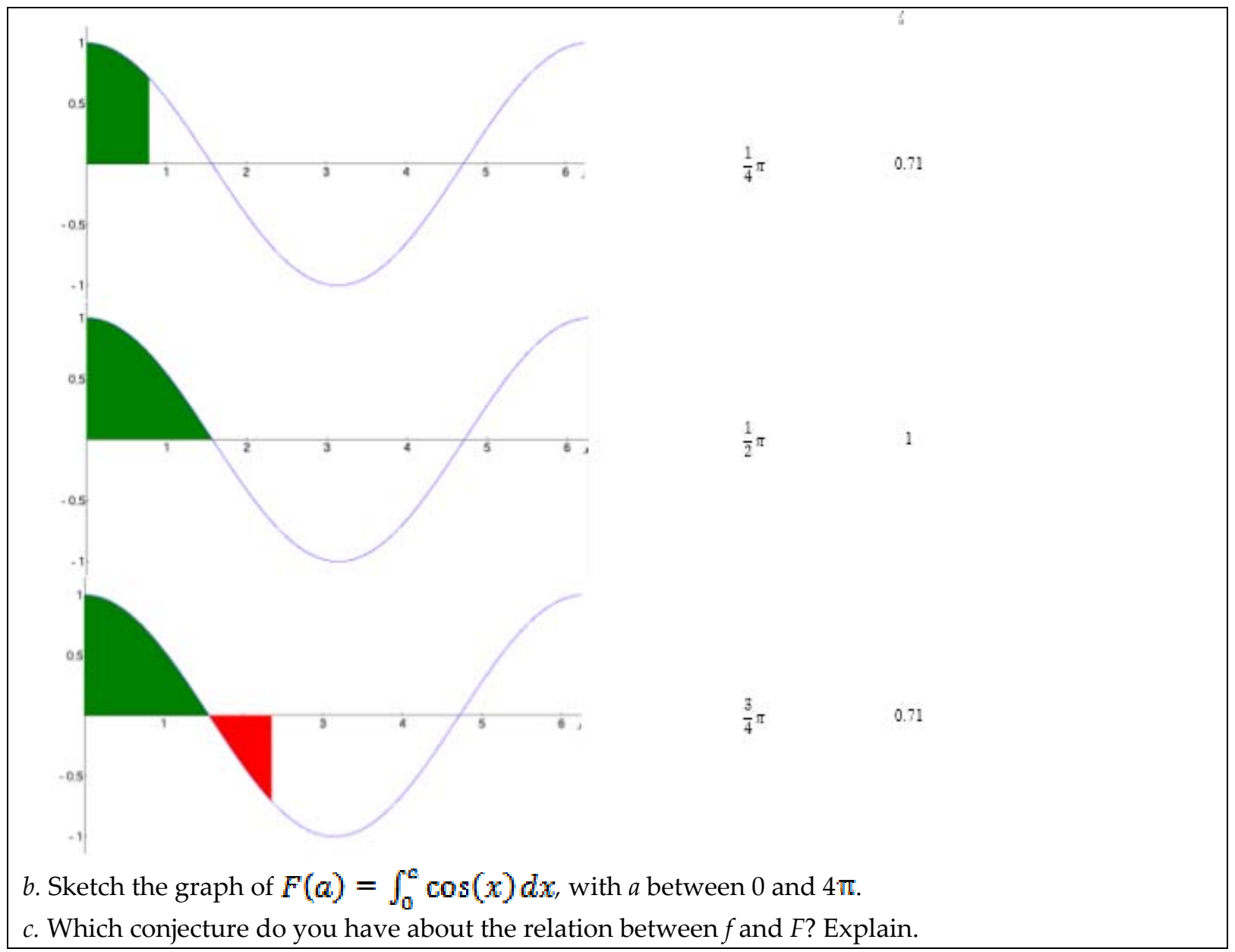

Figure 6. Task 11

Collaborative mathematical reasoning. The students coloured the areas and calculated the corresponding function values (Figure 7).

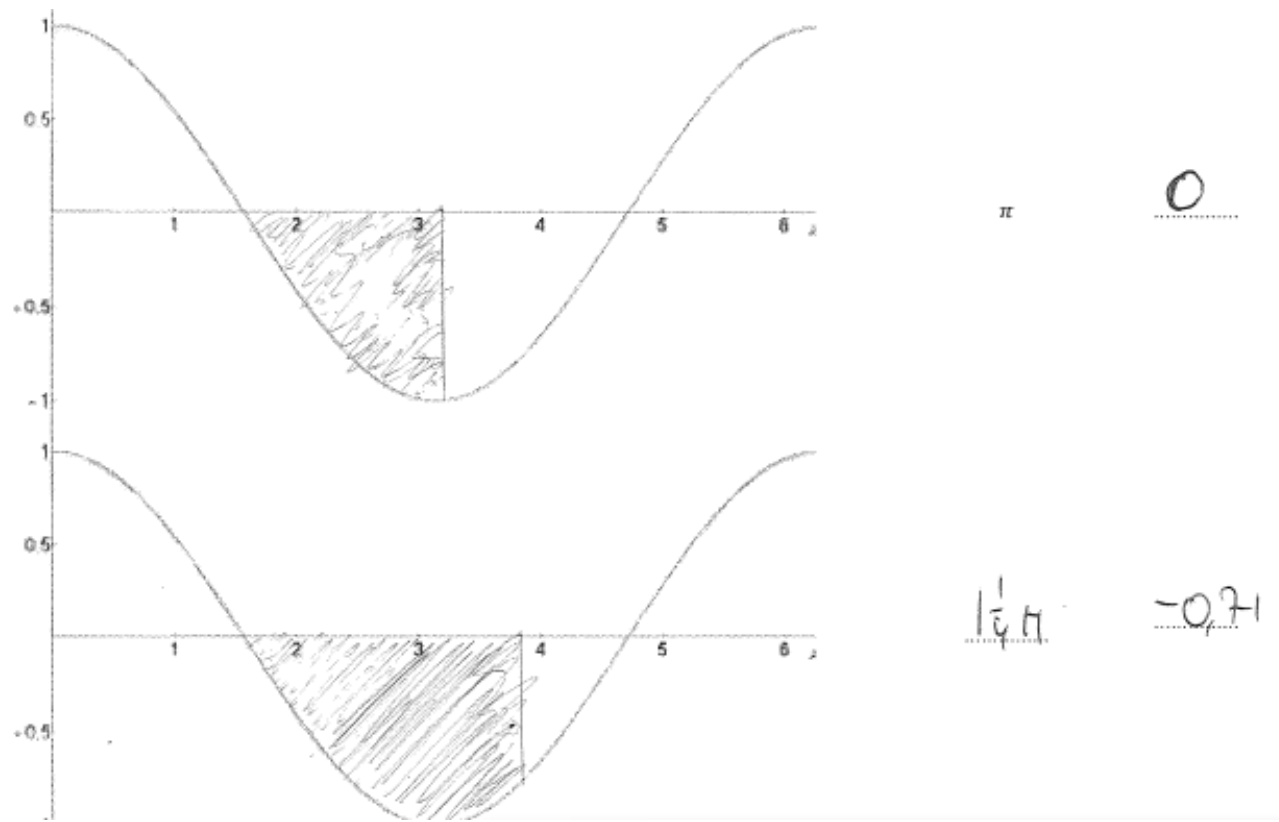

Figure 7. Students' solution to task 11a 
As we expected students realized that each coloured area should be coupled to a number. By doing this the area becomes a number, which makes it possible to conceptualize it as a value of an integral function. When calculating the values students doubted about the value of the area being zero. James explains to Anne how certain signed areas should be combined to the value zero [40], [42] and Anne agrees [41]. Brian initially struggles to imagine negative values (he predicts the following value incorrectly [43]). But through the dialogue with the other students and James explanation [44]-[48] he finally realized that the integral values can take negative values.

40 J The number equals zero. Look, because here it goes on for a while, because you have this exactly there, too.

41 A Yes, that is true.

$42 \mathrm{~J}$ So together they become zero. Write that down. This is that first one. That is zero, anyhow. And then we add an extra piece.

43 B That becomes 1 again.

44 J No, no, no, because that is... Then you have to calculate the other way around. What is added is this.

45 B Yes.

$46 \mathrm{~J} \quad$ So it becomes minus 0.71 .

47 B Minus, yes?

$48 \mathrm{~J}$ Yes, because there is more below.

49 A Yes, that is true.

$50 \mathrm{~J} \quad$ And then it becomes minus 1.

Reflection on actual and conjectured learning. Task 11 was sufficiently open to elicit different approaches and views of function that were then discussed by the students. Moreover, producing a joint solution contributed for students to evaluate the mathematical content and reasoning brought up by the discussion and to choose or neglect some contributions. Table 6 summarizes the actual learning with task 11 and aspects of the task.

Table 6. Actual learning with task 11 and aspects of the task

Actual learning and collaborative reasoning

Accumulated area function can take negative values

- Students coloured the areas and calculated the correspondent function values. While doing this the students seem to visualize the area accumulated in a specific interval (action view).

- Students evaluate each other's contributions about mathematical content and reasoning and choose or neglect some contributions.

- Students also discuss whether the integral values should increase or not, and whether they can become negative (object-oriented view). In this case the students seem to visualize the variation of the accumulated area under the graph (process view).

- The area misconception is brought up by one student while calculating the function values and students correct themselves this misunderstanding.

Numerical representation discussed but not generated (lesson ends)

- students think about the different representations of the integral function and mention the possibility to construct a table; they are still discussing this when the lesson ends.

Aspects of the task that supports the learning

- It requires students to colour the area and relate it to a number .

- The construction of the global graph elicits covariational reasoning

- The openness of the task elicits different views of function (action, process and as object). 
- $\quad$ It requires a joint solution.

The integral function as an object

Initial conjectures about students' learning. In task 13 (Figure 8) students are requested to explore the graph of an integral function with a GeoGebra application. They should generate a graphical representation and explain in words the meaning of its characteristics. The tasks is expected to

1. motivate the students to experiment with different values and to imagine the integralfunction values varying and the graph of this variation (covariational reasoning);

2. to provoke the conflict that the integral function can take negative values;

3. elicit different views of the integral function: as pointwise correspondence (give a few values of $F(a)$ ); as a covariational process (indicate how the graph of $f$ shows whether $F$ increases or decreases) and as an object (describe in words using a sketch what the graph of the integral function looks like). While students are trying to describe, understand and explain the different aspects of the integral function we expect that this motivates students to think about the integral function as an abstract object.

Given the function $f(x)=\frac{3}{2} x(4-x)$. The coloured region is enclosed by the $x$-axis, the graph of $f$ and the line $x=a$ starting from $a=1$.

The area of the coloured region can be described using the integral function $F(a)=\int_{1}^{a} f(x) d x$.

You get different values for the integral function $F$ as you vary the upper limit $a$. Using GeoGebra you'll investigate the graph of the integral function.

In the figures below, you see the graph of $f$ and the area of the coloured region for $a=2.53$.

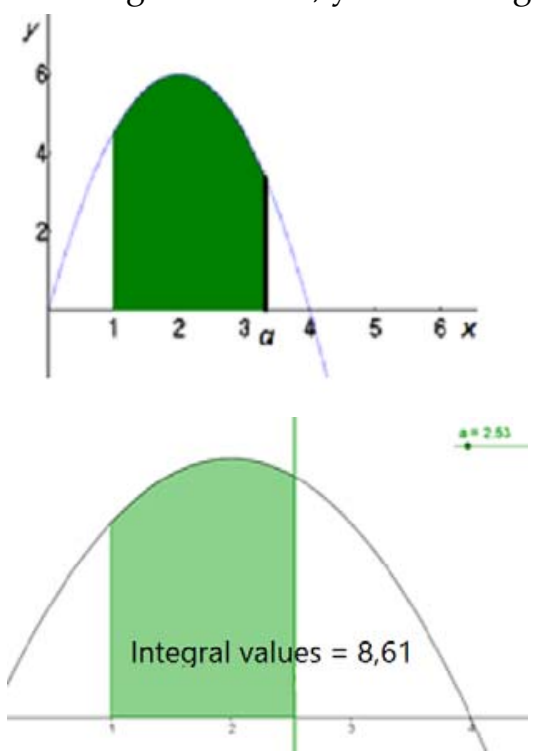

The parameter $a$ can be changed using the slider. When you do this, the values of the integral function change, whence the area of the coloured region.

a. Open de application

b. Describe in words using a sketch what the graph of the integral function looks like. Give a few values of $F(a)$. Indicate how the graph of $f$ shows whether $F$ increases or decreases. Explain the meaning of $F(a)=0$.

Figure 8. Task 13

Collaborative mathematical reasoning. Initially students struggled to distinguish the graph the graph of the function $f$ from the graph representing the area under the graph of $f$ [46]. The students questioned 
each other [42], [44], provide answers [43], [45] and elaborations of previous utterances [46], [49]. During this clarification of the task students shared a variety of meanings related with the integralas-function: as the area under the graph [46], [48]; as anti-derivative [45] and as integral [49].

42 A This is just the graph of $f$, isn't it?

43 J Yes

44 A Then what is $f$ ?

45 B That is the primitive (anti-derivative)...

$46 \mathrm{~J} \quad f(a)$ is this, so it is the area.

47 B Yes, that, yes

48 A Ah, the area

49 J Yes, the integral, so...

The GeoGebra-application elicits students' exploration of the graphical representation of the integral function; they observe how the area-function seems to vary and increases until a certain value [50][54]; then they also observe how it decreases and takes negative values [62]-[67], which also involves covariational reasoning. As in task 11 students face some confusion when confronted with the areafunction taking negative values [67]-[68] but, they overcome this conflict. Anne elaborates on James' explanation [66] and reconstructs her previous idea that the area should become bigger [53], [68], [70]. James reconstructs his general idea making it more specific [69].

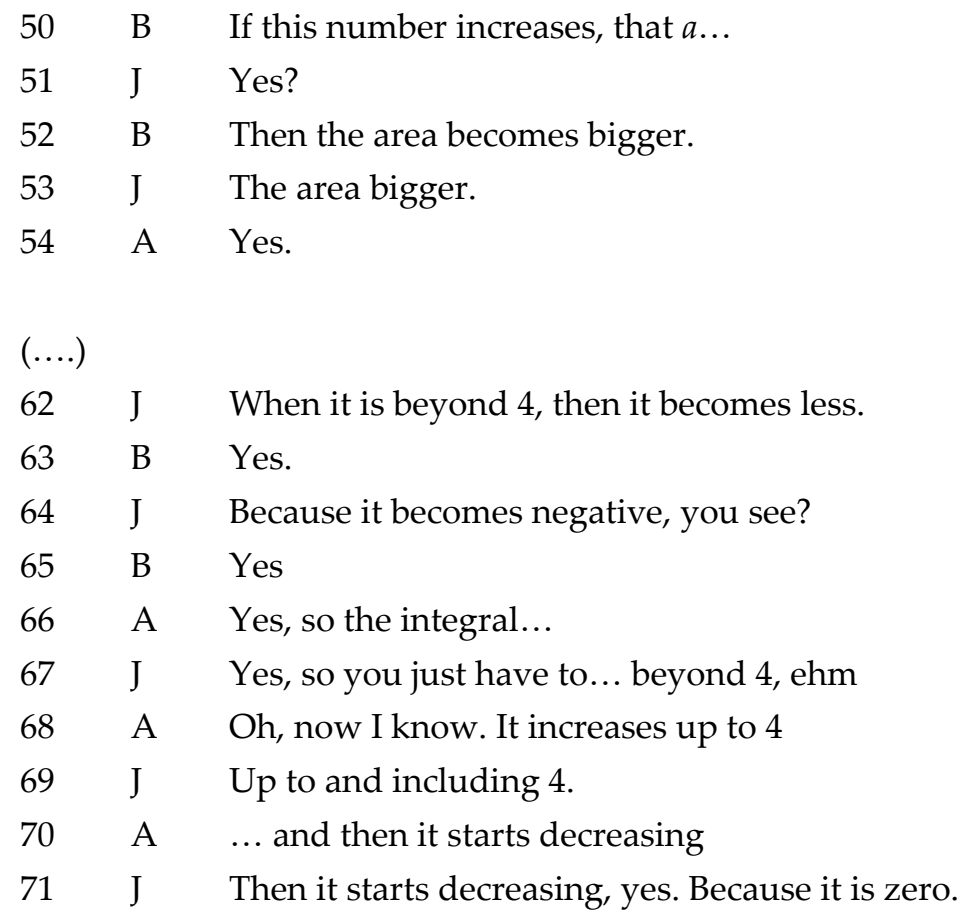

The students' solution to task 13 is presented in Fig. 9. 


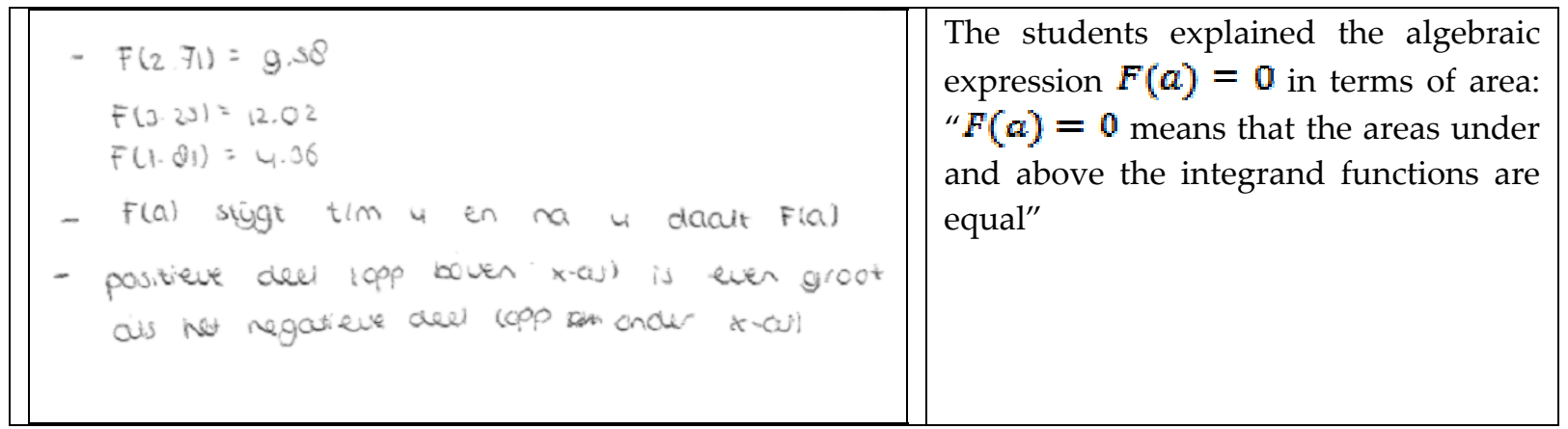

Figure 9. Students' solution to task 13

Reflection on actual and conjectured learning. As we expected the task bring to the fore different views of the integral function. Also, students engaged in covariational reasoning and they were triggered to think about the integral function as having negative values even though it takes the form of the area under the graph. In table 7 we summarize these and other results of the actual learning with the task.

Table 7. Actual learning with task 13 and aspects of the task

\section{Actual learning and collaborative reasoning}

View of the integral function as the amount of accumulated and signed area as the upper limit varies

- Students provide specific values for the integral function that they calculate with the GeoGebraapplication (action view).

- Students explore the variation of the upper limit with the GeoGebra-application but without attention for the different integral function values.

- Students realize with the GeoGebra-application that the integral function decreases and it takes negative values and they discuss about the integral function having negative values even though it takes the form of the area under the graph (object view).

- Students reason using covariation while trying to explain the form of the graph of the integral function (process view).

- students provide descriptions of the integral as primitive and as area.

Algebraically $F(\boldsymbol{a})=\boldsymbol{a}$ is explained in terms of cancelling signed area's

- $\quad$ students explained the algebraic expression $F(a)=0$ in terms of area.

Aspects of the task that supports the learning

- The GeoGebra-application and the figure on the task elicit students exploration.

- $\quad$ The integral function takes negative values.

- It requires students to explain the integral function verbally and graphically.

- It produces a joint solution.

Overview of students' learning of the integral concept

The results regarding the mathematical reasoning emerging in the group in the four lessons. are summarized in Table 8. In the left column aspects of the integral function that we observed by the students are specified for each part of the learning sequence (second column). In columns four and five we recorded the source of the evidence that we found in the data.

Table 8. Students' collaborative learning of the integral concept

\begin{tabular}{|l|l|l|l|l|c|}
\hline Students' learning of the integral as function & $\begin{array}{l}\text { Learning } \\
\text { sequence }\end{array}$ & $\begin{array}{l}\text { Task } \\
\text { example }\end{array}$ & $\begin{array}{l}\text { Written } \\
\text { solutions }\end{array}$ & Dialogue \\
\hline \multicolumn{6}{|c|}{ Intuitive understanding of the integral concept (section 4.1) } \\
\hline Phenomenological and context specific & \multirow{2}{*}{ Part 1 } & Task 1a & & + \\
\cline { 1 - 3 } & & & + & + \\
\hline
\end{tabular}




\begin{tabular}{|c|c|c|c|c|}
\hline \multicolumn{5}{|c|}{ Numerical representation of the integral as accumulation function (section 4.2) } \\
\hline $\begin{array}{l}\text { Numerical representation (table) of the } \\
\text { accumulated distance involving an action view }\end{array}$ & \multirow{3}{*}{ Part I } & \multirow{3}{*}{ Task $1 \mathrm{~b}$} & + & + \\
\hline $\begin{array}{l}\text { Different meanings of accumulated distance, } \\
\text { including area under the graph }\end{array}$ & & & & + \\
\hline $\begin{array}{l}\text { Accumulated distance as the sum of } \\
\text { multiplicative quantities }\end{array}$ & & & & + \\
\hline \multicolumn{5}{|c|}{ Graphical representation of the integral as accumulation function (section 4.3) } \\
\hline Thinking and interpretation of velocity graph & \multirow{3}{*}{ Part II } & \multirow{3}{*}{ Task $3 b$} & & + \\
\hline Doubt about the best graph to use & & & & + \\
\hline $\begin{array}{l}\text { Graphical representation of an accumulated } \\
\text { distance graph involving a process view }\end{array}$ & & & + & + \\
\hline \multicolumn{5}{|c|}{ Rate of change of the accumulation function (section 4.4) } \\
\hline $\begin{array}{l}\text { Accumulated area function can take negative } \\
\text { values (action, process, object view) }\end{array}$ & \multirow{2}{*}{ Part III } & \multirow{2}{*}{ Task 11} & + & + \\
\hline $\begin{array}{l}\text { Numerical representation discussed but not } \\
\text { generated (lesson ends) }\end{array}$ & & & & + \\
\hline \multicolumn{5}{|c|}{$\begin{array}{l}\text { Integral function as object (see 4.5) } \\
\end{array}$} \\
\hline $\begin{array}{l}\text { View of the integral function as the amount of } \\
\text { accumulated and signed area as the upper limit } \\
\text { varies }\end{array}$ & \multirow[t]{2}{*}{ Part IV } & \multirow[t]{2}{*}{ Task 13} & + & + \\
\hline $\begin{array}{l}\text { Algebraically } F(a)=0 \text { is explained in terms } \\
\text { of cancelling signed area's }\end{array}$ & & & + & + \\
\hline
\end{tabular}

The quantitative results of the analysis of the collaborative reasoning regard the frequency of students' participation in the dialogue and the quality of this participation. These results are respectively presented in Tables 4 and 5. The results show that the group engaged in dialogic processes that can led to collaborative knowledge construction (Fischer et al., 21002), although students contributed differently to the group reasoning. James and Brian participated more in the dialogue than Anne (table 9). Furthermore, James questions, criticizes and elaborates more often than the other students (Table 10). Brian provides more often agreement and answers with no elaboration. Anne's contribution is smaller than the other two students but of higher quality than Brian's.

Table 9. Frequency of students' participation in the task-dialogue

\begin{tabular}{ccccc} 
& James & Anne & Brian & $\begin{array}{c}\text { Total number of } \\
\text { utterances per task }\end{array}$ \\
\hline Task 1a & 19 & 12 & 27 & 58 \\
Task 1b & 112 & 64 & 104 & 280 \\
Task 3 & 73 & 33 & 54 & 160 \\
Task 11 & 64 & 23 & 59 & 146 \\
Task 13 & 35 & 23 & 31 & 89 \\
\hline Total number of & & & & 800 \\
utterances per student & 333 & 165 & 302 & \\
\hline
\end{tabular}


Table 10. Frequency of the categories of co-construction

\begin{tabular}{lcccc}
\hline & James & Anne & Brian & $\begin{array}{c}\text { Total number of utterances } \\
\text { per category }\end{array}$ \\
Reconstruction & 10 & 7 & 7 & 24 \\
Rejection/criticize & 49 & 18 & 18 & 85 \\
Request & 30 & 20 & 22 & 72 \\
Elaboration & 113 & 41 & 68 & 222 \\
Agreement/answer & 33 & 30 & 88 & 151 \\
Other/out of task & 76 & 50 & 82 & 206 \\
\hline Total number of & 309 & 166 & 285 & 760 \\
utterances per student & & & &
\end{tabular}

\section{Main findings and further directions}

Integrals in high school are traditionally taught in a mechanical style with a focus on procedures and calculations. There is a of lack instructional tasks that can help students to think and communicate about integrals in conceptual terms (Kouropatov \& Dreyfus, 2013). In this study we developed an instructional approach (the integral-as-accumulation function approach) and we provide evidence that it can meet this need.

\section{Collaborative learning trajectory for the integral concept}

The main finding is the students learning trajectory that provides knowledge about the way students learn the integral concept. The trajectory that we observed has a collective nature as we focused on processes of collaborative knowledge construction. It is summarized in Table 8 . According to this learning trajectory one aspect of students learning is their use of the accumulation function. That can provide a basis for thinking, reasoning and communicating about integrals in intuitive ways.

We have seen that imagining accumulating quantitates in context situations helped students to generate a variety of mathematical representation of the variation of these accumulating quantitates over an interval (verbally, numerical, graphical). In the train task (task 1) students had difficulty in mathematically interpreting and representing the distance as a function of time. The cue to overcome this difficulty was James' use of the notion of accumulated distance. The student recalled his intuitive knowledge and experience with contexts by dynamic events (the distance accumulating over time while the train is travelling.) This knowledge was shared and integrated by the group and applied to generate a joint table the distance accumulating over time.

These findings suggest that the thought of quantities accumulating encouraged the group to decide for a certain solution (e.g. the graph of the distance accumulating over time was a more efficient solution to task 3 than the velocity graph.) and to generate an appropriate mathematical representation to solve the task (e.g. the generation of a table of the distance accumulating over time in task 1; the generation of a graph of the areas accumulating in task 11; and the interpretation of the accumulating values of the function in task 13). Situations such as these have possibly motivated students to think about diverse views of the integral-as-function. and to switch from one view to the other.

A second aspect of students' learning in the trajectory regards the way they handle conflicts about the signed-area. Although students struggled with the idea that accumulated quantities can be decreasing they were capable, collectively to overcome this difficulty. This might support students to perceive better the relationship between the process of accumulation and the area under a curve. The IAF- 
approach has contributed to this by including tasks that provoke such situations. In tasks 11 and 13 students were facing some conflict and they overcome themselves the (mis)conception that integrals cannot be negative. Several researches (Nguyen \& Rebello, 2011; Sealey, 2006) show that the interpretations of the integral as an "area under a curve," can limit students' applicability of the integral to solve problems. According to the authors the students don't necessarily understand the relationship between the process of accumulation and the area under a curve. Therefore, they failed to apply the notion of integral as area under a curve in novel situations.

A third aspect of students' learning with the trajectory regards the dialogic process of the group of students while solving the tasks together. The group shared, transformed and elaborated solutions in almost all the tasks. For instance the sharing of the idea of accumulation was useful to alert some students to the fact that integral functions can take negative values. It was James' explanation that 'when the graph is beyond 4, then it becomes less' that lead Anne to take notice and improve her idea: "Oh, now I know. It increases up to four". The small-group dialogue facilitated the correction of this and other misconceptions. These results extend the findings in Mueller \& Yankelewitz' (2014) about collaborative learning. They found that allowing students to discuss invalid arguments motivated students' use of varied reasoning and clear up some (mis)understandings.

In our case the tasks did not prompt explicitly invalid arguments. Alternatively, these were brought up by the students themselves. It was during the discussion of these differences that 'invalid' (and valid) arguments arise. All students contributed in a significant manner to the dialogue, even though some students participated more often than other. That was the case of dialogue in which the notion of accumulation was used as a warrant to support or evaluate thoughts and claims. This was often initiated by the same student (James) and only later integrated by the other students. However, we want to remark that Anne and Brian did not merely accept James suggestions and they remained critical until James' arguments made sense to them. Only then they modified their claims. This is an interesting result since in traditional education students find it difficult to validate mathematical solutions. Also, they often depend on an external source for this like the teacher or the textbook (Lithner, 2008; Schoenfeld, 1992). In fact, during the collaborative lessons, the students rarely asked the teacher to evaluate their work. It is possible the idea of accumulation provides some sense of confidence to act independently from the teacher and tried to evaluate their work for themselves.

However, students' learning of the integral concept in terms of integral-as-function was not unproblematic. We observed students' obstacles in interpreting and applying general knowledge about functions. For instances students' difficulty in defining a pointwise correspondence between time and total distance in the train task. These difficulties are apparently connected with a limited understanding of the function concept. Another kind of problem is related with the tasks. Research has shown students' ability to produce a proper mathematical representation can be hindered or enhanced by students' mental image of a problem's context. Students might not imagine a quantitative structure as it was intended by the task (Moore \& Carlson, 2012). In this case they can fail to determine graphs or formulas that correctly represent how the quantities are related and change together. For instance in the task train travel we saw that Brian and Anne were not thinking in functional terms. Their focus was on the relation between velocity and distance. It is possible this has limited their perception of the notions of accumulation and accumulation function.

Another key (and practical) finding of this study is the learning sequence. The learning tasks had a substantial influence in the way the collaborative setting elicit students' reasoning and thinking. A purely mechanistic and formal approach to the topic would not support the kind of thinking processes and interaction among students that we observed and described in sections 4.1-4.6. In the light of these findings, the learning sequence that we present here seems to be promising but there is much room for improvement. 
Directions to improve the learning sequence

The following list points some directions for the re-design of the tasks and the learning sequence. They can be valuable for teachers, mathematics educators and researchers who are interested in teaching and learning integrals in ways that foster collaborative reasoning and thinking about the integral-as-function.

Extend the learning sequence to a learning trajectory around the notion of accumulation. We have seen that overall, the notion of a quantity accumulating over time was meaningful to the students and encouraged them to think and communicate about the integral function. It wasn't always in the way we had in mind, what doesn't mean it was less effective. This notion can be introduced in an earlier school level (we believe it could be introduced already in primary education.) Using a variety of contexts, depending on the school level, age of the students and level of knowledge. Students learning descriptions in tables 3-7 can be used as starting point to setup a hypothetical learning trajectory about integrals, which can be refined through research.

Include broad variety of authentic contexts and open tasks. One of the learning gains for the students that may occur, while they are working with contexts is that these ones support students' thinking in specific ways. For instance the generation of a numerical table appeared to be more suitable to motivate an action view of function while the generation of a global graph elicited a process view and covariational reasoning. For instance, while constructing the graph globally, Brian was trying to imagine what the graph would look like. Moreover, alternative approaches and views of function are more probably to occur when the context is rich and the task is open. The best example we found in our data was the train task. Other contexts than distance-velocity of areas should be additionally included in the learning sequence.

Opportunity to validate the correctness of solutions and statements independently. We have seen that through the dialogue several opportunities arise for students to evaluate the mathematical content and reasoning. We have seen the students worked most of the time by themselves and they relied on their own judgment to choose or neglect some contributions to the discussion. One aspect that was missing represents the connection of essential ideas about integrals. The teacher plays an essential role with regard to this (Stein \& Smith, 2007).

Integral-learning specific activities. Some of the aspects of the task reported in tables 6-10 were specific to the learning of the integral. They can be utilized to develop tasks with this aim. One of these aspects is to foster covariational reasoning. Other aspect is anticipating the area-misconception. When the integral is conceptualized as area under the graph, it often happens that students believe that the integral must be always positive. We saw this happening with Brian. We provoke this situation by using examples of accumulation functions that would admit negative values.

Generation of a joint explanation, mathematical representation or solution. Some tasks are more suitable to elicit collaborative reasoning while others are better suited as individual assignments. One characteristic that we found to be essential for collaborative reasoning was the joint solution. This fostered students to collaborate, rather than just distribute the work. As we already mentioned, the use of context does not always led to the appropriate 'association', but it does lead to diversity. So while James pitched the idea of accumulation function, whereas Anne associated the context with the science lessons. This diversity can be positive if this difference allows comparing alternative views on the similar situation without disturbing the emergence of appropriate mathematical ideas and models. 


\section{Significance of the study to practice and suggestions for further research}

The research methodology used in this study was a case study observation and involved one group of three students. Therefore the observed learning process is an example that cannot be generalized. The results may be different with different teacher intervention, other students and using different tasks. We consider this a major limitation of this study. On the other side, this method allowed us to gain detailed insight into students learning of integrals based on the accumulated function at high school which is still a yet unexplored domain. We were able to observe students reasoning about integrals and to develop a possible learning trajectory (Table 8) for this learning.

The development of a hypothetical learning trajectory on this topic could be subject of research. In particular, we observed how the notion of accumulation and accumulation function have contributed to this learning. These are aspects which have not been described before in previous research on the learning of integrals, and which can contribute to the development of instruction and instructional moves for teachers to support a more conceptual approach to integrals.

\section{Acknowledgements}

This research was supported by the Centre for Applied Research in Education of the University of Applies Sciences of Amsterdam and by Delft University of Technology.

\section{References}

Bakker, A. and van Eerde, D. (2013). An introduction to design-based research with an example from statistics education. In A. Bikner-Ahsbahs, C. Knipping, \& N. Presmeg (Eds.), Doing qualitative research: methodology and methods in mathematics education. New York: Springer.

Barron, B. (2000). Achieving coordination in collaborative problem-solving groups. The Journal of the Learning Sciences, 9(4), 403436.

Bergqvist, T., Lithner, J. and Sumpter, L. (2008). Upper secondary students' task reasoning. International Journal of Mathematical Education in Science and Technology, 39(1), 1-12.

Carlson, M., Jacobs, S., Coe, E., Larsen, S., \& Hsu, E. (2002). Applying covariational reasoning while modeling dynamic events: a framework and a study. Journal for Research in Mathematics Education, 33(5), 352-378.

Cobb, P., Wood, T., Yackel, E., \& McNeal, B. (1992). Characteristics of classroom mathematics traditions: An interactional analysis. American educational research journal, 29(3), 573-604.

Cobb, P., \& Whitenack, J. W. (1996). A method for conducting longitudinal analyses of classroom video-recordings and transcripts. Educational studies in mathematics, 30(3), 213-228.

Dekker, R., \& Elshout-Mohr, M. (1998). A process model for interaction and mathematical level raising. Educational Studies in Mathematics, 35(3), 303-314.

Dekker, R., \& Elshout-Mohr, M. (2004). Teacher interventions aimed at mathematical level raising during collaborative learning. Educational Studies in Mathematics, 56(1), 39-65.

Dekker, R., Elshout-Mohr, M. \& Wood, T. (2004). Working together on assignments: multiple analysis of learning events. In J. v. d. Linden \& P. Renshaw (Eds.), Dialogic Learning (pp. 145-170). Dordrecht: Kluwer Academic Publishers.

Dillenbourg, P., Baker P., Blaye M., O’Malley, C. (1995). The evolution of research on collaborative learning. In E. Spada \& P. Reiman (Eds.), Learning in Humans and Machine: Towards an interdisciplinary learning science. pp. 189 - 211. Oxford: Elsevier.

Fischer, F., Bruhn, J., Gräsel, C., \& Mandl, H. (2002). Fostering collaborative knowledge construction with visualization tools. Learning and Instruction, 12(2), 213-232.

Gray, E. M., \& Tall, D. O. (1994). Duality, ambiguity, and flexibility: A "proceptual" view of simple arithmetic. Journal for research in Mathematics Education, 116-140.

Harel, G., \& Sowder, L. (2007). Toward comprehensive perspectives on the learning and teaching of proof. Second handbook of research on mathematics teaching and learning, 2, 805-842.

Jones, K. (2000). Providing a foundation for deductive reasoning: students' interpretations when using Dynamic Geometry software and their evolving mathematical explanations. Educational studies in mathematics, 44(1-2), 55-85

Kouropatov, A., \& Dreyfus, T. (2013). Constructing the integral concept on the basis of the idea of accumulation: suggestion for a high school curriculum. International Journal of Mathematical Education in Science and Technology, 44(5), 641-651.

Lithner, J. (2003). Students' mathematical reasoning in university textbook exercises. Educational studies in mathematics, 52(1), 2955.

Lithner, J. (2008). A research framework for creative and imitative reasoning. Educational Studies in Mathematics, 67(3), 255-276 
Moore, K. C., \& Carlson, M. P. (2012). Students' images of problem contexts when solving applied problems. The Journal of Mathematical Behavior, 31(1), 48-59.

Mueller, M., \& Yankelewitz, D. (2014). Fallacious Argumentation in Student Reasoning: Are There Benefits?. European Journal of Science and Mathematics Education, 2(1), 27-38.

Nguyen, D. H., \& Rebello, N. S. (2011). Students' understanding and application of the area under the curve concept in physics problems. Physical Review Special Topics-Physics Education Research, 7(1)

Sfard, A. (1991). On the dual nature of mathematical conceptions: Reflections on processes and objects as different sides of the same coin. Educational studies in mathematics, 22(1), 1-36.

Slavit, D. (1997). An alternate route to the reification of function. Educational Studies in Mathematics, 33(3), 259-281.

Tall, D. (1996). Functions and Calculus. In A. J. B. e. al (Ed.), International Handbook of Mathematics Education (pp. 289 - 325): Kluwer Academic Publishers.

Tall, D. O. (2009). Dynamic mathematics and the blending of knowledge structures in the calculus. ZDM, 41(4), 481-492.

Thompson, P. W. (1994). Images of rate and operational understanding of the fundamental theorem of calculus. In Learning Mathematics (pp. 125-170). Springer Netherlands.

Thompson, P. W., \& Silverman, J. (2008). The concept of accumulation in calculus. In M. P. Carlson \& C. Rasmussen (Eds.), Making the connection: Research and teaching in undergraduate mathematics (pp. 43-52). Washington, DC: Mathematical Association of America.

Rasmussen, C., Marrongelle, K., \& Borba, M. C. (2014). Research on calculus: what do we know and where do we need to go? $Z D M, 46(4)$, 507-515.

Webb, N. M., Nemer, K. M., \& Ing, M. (2006). Small-group reflections: Parallels between teacher discourse and student behavior in peer-directed groups. The Journal of the Learning Sciences, 15(1), 63-119.

Webb, N. M., Franke, M. L., Wong, J., Fernandez, C. H., Shin, N., \& Turrou, A. C. (2014). Engaging with others' mathematical ideas: Interrelationships among student participation, teachers' instructional practices, and learning. International Journal of Educational Research, 63, 79-93.

Yackel, E. (2001). Explanation, Justification and Argumentation in Mathematics Classrooms.

Yackel, E. (2002). What we can learn from analyzing the teacher's role in collective argumentation. The Journal of Mathematical Behavior, 21(4), 423-440.

\section{Appendix}

Categories for analysis of collaborative reasoning

\begin{tabular}{|c|c|c|}
\hline Category & Description & Example \\
\hline Answer & $\begin{array}{l}\text { Answer to a question from another student. If an } \\
\text { explanation is added with new elements in it, } \\
\text { then it will be linked with other codes. }\end{array}$ & $\begin{array}{l}\text { Yes, I just know it. } \\
\text { I don't know. }\end{array}$ \\
\hline Agreement & $\begin{array}{l}\text { Agreement with previous statement of another } \\
\text { student or repeating other students' statement; if } \\
\text { an explanation is added with new elements in it, } \\
\text { then it will be linked with other codes. }\end{array}$ & $\begin{array}{l}\text { Yes, I think in the same way. } \\
\text { Yes. } \\
36\end{array}$ \\
\hline Elaboration & $\begin{array}{l}\text { Mathematical related statement that connects and } \\
\text { extends a previous statement of another student } \\
\text { or from the same student; it may be a rephrasing } \\
\text { of the same statement. }\end{array}$ & $\begin{array}{l}\text { Yes, indeed. Here is just one and there } \\
\text { it will be } 7 \times 1 \text {. }\end{array}$ \\
\hline Questioning & Question that requires elaboration & Why do you think that? \\
\hline Criticism & $\begin{array}{l}\text { One student criticizes another student or express } \\
\text { criticism about own thoughts and actions. } \\
\text { Usually statements within this category contain } \\
\text { words as 'but' or 'perhaps'. It also includes } \\
\text { rejection of an idea / solution / proposal from } \\
\text { someone else (or from the person himself). }\end{array}$ & $\begin{array}{l}\text { But, than it takes very rare steps. } \\
\text { No, its wrong. You have to add } 15 . \\
\text { Perhaps we should add one more } \\
\text { value? }\end{array}$ \\
\hline Reconstruction & $\begin{array}{l}\text { Correcting or refining an earlier statement, which } \\
\text { can be an opinion, a conviction or an idea. The } \\
\text { statement may be from someone else or from the }\end{array}$ & $\begin{array}{l}\text { Aahhh.... there are only four values } \\
\text { instead of three. } \\
\text { But you cannot just merge the three }\end{array}$ \\
\hline
\end{tabular}




\begin{tabular}{|l|l|l|}
\hline Category & Description & Example \\
\hline Other & $\begin{array}{l}\text { person self. Reconstruction is a form of } \\
\text { elaboration in which there is change in the way } \\
\text { of thinking has taken place. }\end{array}$ & $\begin{array}{l}\text { formulas. You have the first five } \\
\text { seconds, then the delay and then the } \\
\text { constant speed. }\end{array}$ \\
\hline $\begin{array}{l}\text { Any statement that does not fit the other } \\
\text { categories; it can be statements that do not have a } \\
\text { clear function in the conversation or reading } \\
\text { aloud text of the assignment. }\end{array}$ & $\begin{array}{l}\text { I will pick up my calculator. } \\
\text { This text is not important. }\end{array}$ \\
\hline
\end{tabular}

NB1: An utterance can be incorrect from a mathematical point of view. In that case, the additional code 'error' was added.

NB2: An utterance that falls in more than one category receives the code of the 'higher category'. For instance, 'elaboration' and 'criticism' would get the code 'criticism', as posing a criticism involves also elaboration

\footnotetext{
${ }^{i}$ Proceptual thinking is defined as a combination of conceptual and procedural thinking. It includes the flexible to view symbolism either as a trigger for carrying out a procedure or as the representation of a mental object that may be decomposed, recomposed, and manipulated at a higher level (p.125, Gray \& Tall,1994)
} 